\title{
An Overview on the Trends and Challenges of Advanced Manufacturing
}

\author{
N. Sivasubramanian* Prof S. Sheik Mohamed** \\ ${ }^{1}$ Research Scholar (Part Time), Jamal Institute Of Management, Jamal Mohamed College, Bharathidasan University, Trichirapalli, 620020, \\ India \\ ${ }^{2}$ Professor, Jamal Institute Of Management, Jamal Mohamed College, Bharathidasan University, Trichirapalli, 620020, India
}

\begin{abstract}
The growing technological advances in the field of computer systems and associated software, enable the modern society to progress in new era. The manufacturing technology whichis mainly contributing to the development of the country's growth is advancing rapidly due to invasion of advancement in data storage, automation, micro/Nano fabrication, bio manufacturing etc. . The article is an overview of the advances envisaged in the next decades and associated trends and challenges. A number of issues with respect to knowledge management are being addressed. The technology elements and absorption of the same and knowledge transfer related issues are briefly covered. Overviews of potential growth in this field in coming two decades are highlighted.
\end{abstract}

Keywords: advance manufacturing, additive manufacturing, cloud manufacturing, automation, advance materials, technology absorption, computational modelling.

\section{Introduction}

Manufacturing innovations have displaced many of today's traditional manufacturing processes, replacing laborintensive manufacturing processes with automated processes that rely on sensors, robots, and condition-based systems to reduce the need for human interventions, while providing data and information for process oversight and improvement. In future, manufacturers will also increasingly use advanced and custom-designed materials developed using improved computational methods and accelerated experimental techniques. As computational capabilities increase, materials designs, processing, and product engineering will also become more efficient, reducing the time from product concept to production. There is much innovation happening in manufacturing technology research, both in universities as well as in industrial firms, and further productivity gains and game-changing processes are on the horizon. In short period, manufacturing technology is expected to advance to new frontiers, resulting in an increasingly automated and data-intensive manufacturing sector that will likely replace traditional manufacturing. In addition to skill based workforce, knowledge intensive one will be essential to develop and maintain advances in manufacturing

\section{Definition: Advanced Manufacturing}

Advanced manufacturing improves existing or creates entirely new materials, products, and processes via the use of science, engineering, and information technologies; highprecision tools and methods; a high-performance workforce; and innovative business or organizational models.

Typical characteristics of advanced manufacturing are described as:

- An advanced manufacturing production system is capable of furnishing a mix of products in small or large volumes, with both the efficiency of mass production and the flexibility of custom manufacturing, to respond rapidly to customer demand and desired quality.

- Advanced manufacturing results from substantive advancements (whether incremental or breakthrough) over the current state of art in the production of materials and products; these advancements include improvements in manufacturing processes and systems, which are often spurred by breakthroughs in basic science and engineering disciplines. These new systems, which are often referred to as -intelligent" or - -sart" manufacturing systems, integrate computational predictability and operational efficiency.

- Advanced manufacturing produces goods that minimize use of resources while maintaining or improving cost and performance.

\section{Manufacturing Technology Strategies:}

Manufacturing research focus on the transformation of the present factories, towards reusable, flexible, modular, intelligent, digital, virtual, affordable, easy to adapt, easy to operate, easy to maintain and highly reliable one. Manufacturing factories could be visualized as Smart Factories, Virtual Factories, and Digital Factories, the brief functions are as given below

Smart Factories-More automation, better control\& optimization of process Virtual Factories-To manage supply chain, and to create value by integrating products \& services

Digital Factories_To visualize the product before it is realized.

Mainly strategies going to be pursued in future are based on (1) high performance manufacturing to the highest level of accuracy to the order of micro/Nano level (2) exploiting special materials thro processing and handling 


\section{International Journal of Science and Research (IJSR) \\ ISSN (Online): 2319-7064}

Index Copernicus Value (2013): 6.14 | Impact Factor (2014): 5.611

(1)High Performance Manufacturing -strategies

- Flexible, adaptive Production plants for rapid and optimal energy use

- High Precision and Micro manufacturing equipment

- Tools production planning and in situ simulation

- Zero defect manufacturing

\section{(2)Exploiting new materials through} manufacturing

- Net shape manufacturing for structural and functional materials

- New materials manufacturing thro functionalities

- Manufacturing strategies for repair and re use

- Product design using sustainable materials processing technologies

Advanced manufacturing involves one or more of the following elements:

- Advanced products - advanced products refer to technologically complex products, new materials, products with highly sophisticated designs, and other innovative products (Zhou et al. 2009; Rahman 2008).

- Advanced processes and technologies-advanced manufacturing may incorporate a new way of realizing the products with the advanced processes and technologies. Smart manufacturing and enterprise concepts - in recent years, paradigms of -ranufacturing as an ecosystem" have emerged. The term organizations that create and use data and information throughout the product life cycle with the goal of creating flexible manufacturing processes that respond rapidly to changes in demand at low cost minimum impact on the environment with the concept of efficient production and recyclability.

- Advances in science and technology and the convergence of these technologies are a critical building block of advanced manufacturing. The framework therefore highlights the role of breakthroughs in physics, chemistry, materials science, computational modeling, and biology.

Key framework for advances in manufacturing include government investments, availability of a high-performance workforce, intellectual property (IP) regimes (national patent systems), cultural factors, and regulations (Zhou et al. 2009; Kessler, Mittlestadt, and Russell 2007). Also critical to manufacturing are capital, especially early stage venture capital (VC); a workforce knowledgeable in science, technology, engineering, and mathematics (STEM) disciplines; immigration policies; and industry standards.

\section{Global Trends:}

There are four large-scale trends applicable to the manufacturing sector:

- Role of information technology and use of more powerful computers

- Reliance on modeling and simulation on computer aided Design\&Manufacturing
- Rapid changeability of manufacturing in response to customer demands and external impediments

- Acceptance and support of sustainable manufacturing

These trends allow for tighter integration of $R \& D$ and production, mass customization, increased automation, and focus on environmental concerns. The trends in advanced manufacturing technologies for future globally are summarized as below:

- Nano-engineering of Materials and Manufacturing

- Additive and Precision Manufacturing

- Robotics and Adaptive Automation

- Next Generation Electronics Manufacturing

- Continuous Manufacturing Pharmaceuticals and Bio Manufacturing

- Design and Management of Distributed Supply

- Green Sustainable Manufacturing

Several factors have drawn sustainability to the forefront of manufacturing. The first is increasing costs for materials and energy and, perhaps in the future, water. IT based solutions for reducing waste and resource use are growing in popularity and represent one convergence of trends.

\section{Technology Challenges}

- Rapid shrinking of the supplier base due to the out sourcing of manufacturing activities resulting negative impact on the technology development.

- High level of investment needed in R\&D and high risk factor makes technology developers to become a big barrier to technology-based innovation.

- Availability of strategic special Materials, understanding of its characteristics, evaluation technique and processing for designs.

- Simulation capability of electronic device fabrication lags to cope up with the technology development.

- Globally linked manufacturing and enterprise systems and migration to cloud sharing also highlight the increasing need for cyber security and robustness of IT infrastructures.

\section{Techno Managerial Challenges}

Small number of developed countries provide most of technological innovations to the developing countries. The factories in developing countries lack initiative and are taking little efforts to absorb the new technology due to poor infrastructure and insufficient information. Isolation of major R\&D institutions and their linkage with industry face a lot of hurdles due to different rules, laws and regulations. The skill level enhancement, knowledge transfer and sharing are not dynamic to meet the growing demands. Technology transfer related issues predominantly play a major challenge. In future Advance manufacturing technology and innovation is going to be knowledge based and hence knowledge management methods have to be followed.

The advances in manufacturing technology wise is depicted pictorially as in Fig 1. 


\section{International Journal of Science and Research (IJSR)}

ISSN (Online): 2319-7064

Index Copernicus Value (2013): 6.14 | Impact Factor (2014): 5.611

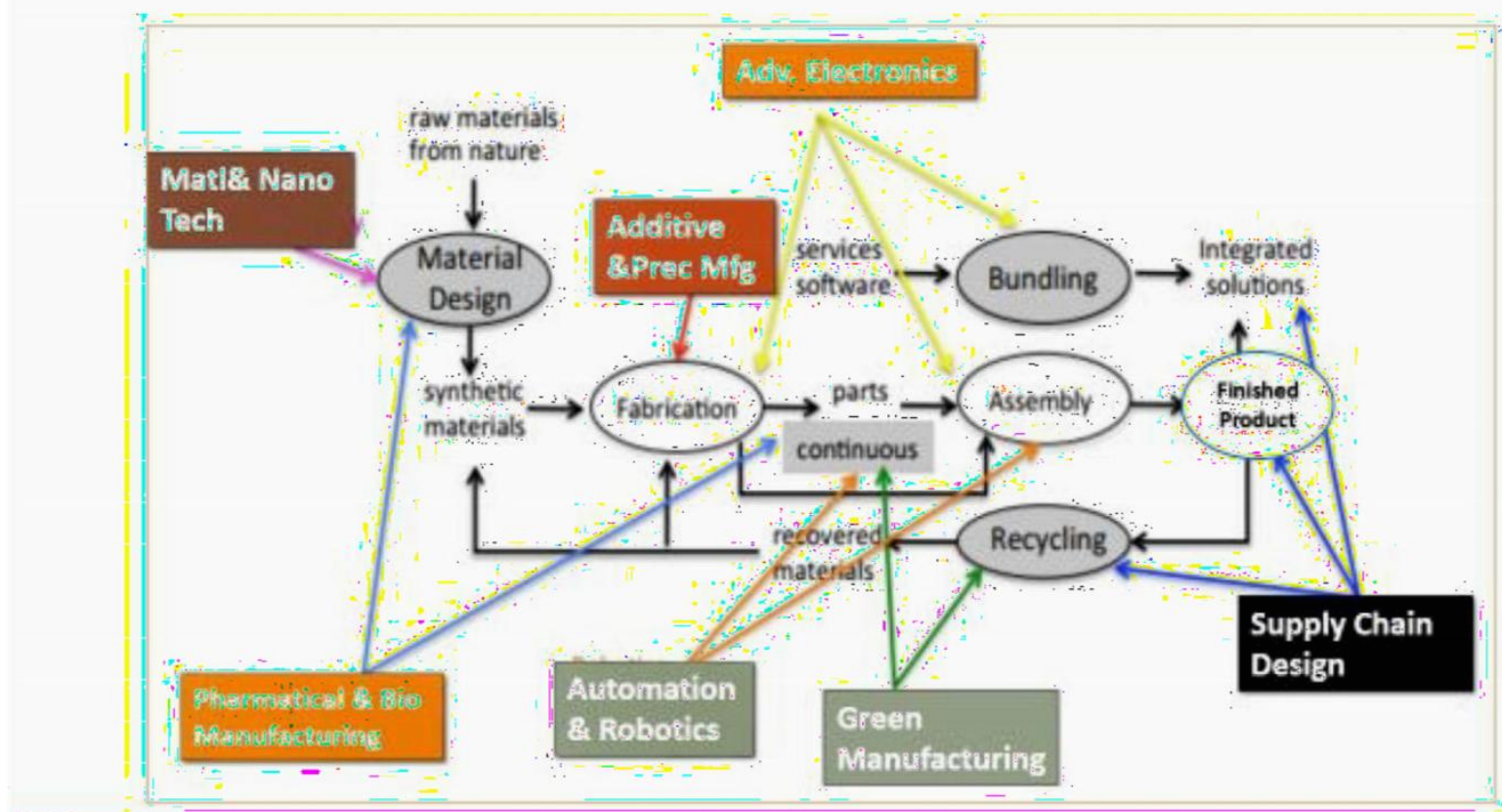

Figure 1: Advance Manufacturing technology -growth pattern

The global trends in advance manufacturing with salient features are given in Fig 2.
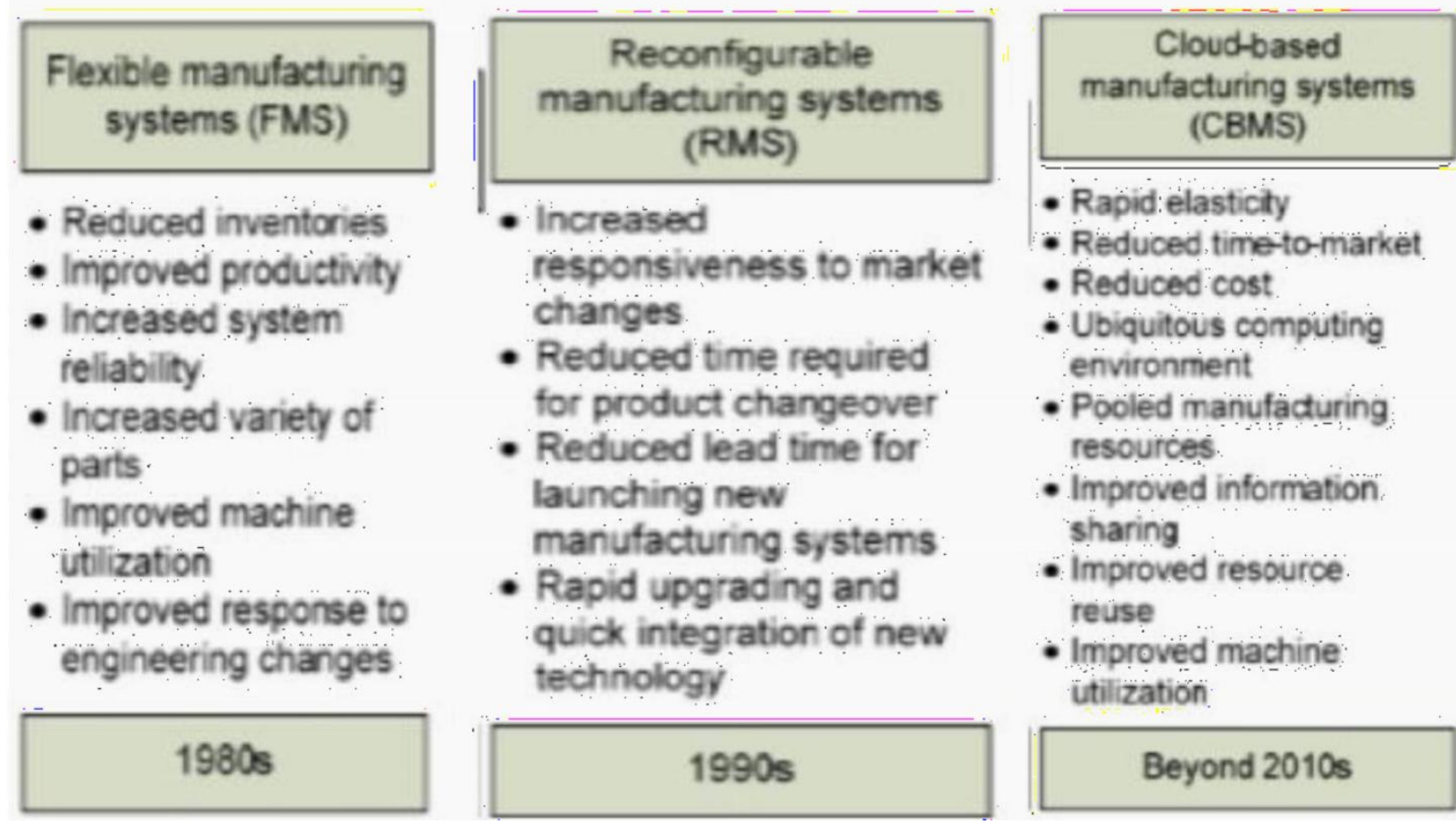

Figure 2: Global Trends in Manufacturing Technology.

\section{Summary}

Future scenarios are going to be an increasingly automated that will continue to rely less on labor-intensive mechanical processes and more on sophisticated informationtechnologyintensive processes. Manufacturing will become increasingly globally linked as automation and digital supply-chain management become the norm across enterprise systems. Advanced manufacturing processes will likely be more energy and resource efficient. Increasing demand for flexibility and customization may lead to the proliferation of additive manufacturing for customized geometry and integrated customized materials. Advances in materials and systems design will likely accelerate and transform manufactured products., to move into advanced manufacturing frontiers, scientific advances are needed, especially interdisciplinary approaches, in multiple areas. Among these are creation of models, databases, and tools for rapid integration of new methods and materials; increasing the quality and availability of materials for additive manufacturing; and increasing fundamental knowledge of

\section{Volume 4 Issue 12, December 2015}




\section{International Journal of Science and Research (IJSR) \\ ISSN (Online): 2319-7064}

Index Copernicus Value (2013): 6.14 | Impact Factor (2014): 5.611

genetics, bioengineering, standardization, and predictability of working with complex genetic circuits.

\section{References}

[1] Kessler, Bill, Eric Mittlestadt, and Jack Russell. 2007. Infrastructure in the Possible Futures of NetworkCentric Manufacturing. Edited by NACFAM Report.

[2] Li Bohu, Zhang Lin, Chai Xudong, Introduction to Cloud Manufacturing publications in ZTE Communication 2010 no 4.

[3] Olivier Weck ,Darci Reed ,Sanjay Sarma and Martin Schmidt, Trends in Advanced Manufacturing Technology Innovation. MIT Study report -2013 .

[4] Rahman, AzmawaniAbd. 2008. Buyer-Supplier Relationships in Advanced

[5] Manufacturing Technology Acquisition and Implementation in Malaysia." International Journal of Economics and Management 2 (1):95-126.

[6] Sivasubramanian N, Global Trends and challenges in Advanced Manufacturing Technology", presentation in conference held on Nov 2015, engineering Society for Aerospace Manufacturing.

[7] Stephanie S. Shipp, Project Leader, et al Emerging Trends In Advanced Manufacturing ,IDA Consolidation Report March 2012.

[8] Zhou, Honggeng, G .Keong Leong, PatrikJonsson, and Chee-Chuong Sum. 2009.

[9]-AComparative Study of Advanced Manufacturing Technology and Manufacturing Infrastructure Investments in Singapore and Sweden." International Journal of Production Economics 120:42-53. 